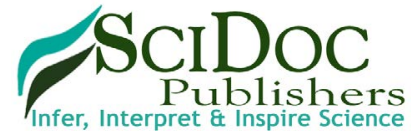

International Journal of Anesthesiology \& Research (IJAR)

ISSN 2332-2780

\title{
Comparative Study of the Effects of Gabapentin and Esmolol on Hemodynamic Response to Laryngoscopy and Intubation
}

Research Article

AB Tiwari ${ }^{* *}$, Bhardwaj $\mathrm{G}^{2}$, Mestha $\mathrm{N}^{3}$

${ }^{1}$ HOD \& Senior Advisor (Anaesthesiology), Air Force Hospital, Kanpur, India.

2 Anaesthesiologist, Military Hospital, Jaipur, India.

${ }^{3}$ Department of Anaesthesiology, Air Force Hospital, Kanpur, India.

\section{Abstract}

The suppression of neurovegetative response to laryngoscopy and intubation has been tried out using several pharmacological agents, such as opioids, local anaesthetics, $\beta$-blockers and $\alpha 2$ agonists. Gabapentin an anticonvulsant, while esmolol is a cardioselective $\beta 1$ blocker and a class II antiarrhythmic, they have shown to attenuate pressor response to direct laryngoscopy and tracheal intubation individually. Given these variable characteristics of two drugs, the present study, a prospective randomized double blind aimed to compare their efficacy against haemodynamic response during intubation and laryngoscopy.

Keywords: Gabapentin; Esmolol; Haemodynamic.

Abbreviations: ASA: American Society Of Anaesthesiologists; BMI: Body Mass Index; SAP: Systolic Arterial Pressure; DAP: Diastolic Arterial Pressure; SBP: Systolic Blood Pressure; DBP: Diastolic Blood Pressure; MAP: Mean Arterial Pressure; RR: Respiratory Rate; RPP: Rate Pressure Product; GA: General Anaesthesia; PLAC: Placebo.

\section{Introduction}

Laryngoscopy and endotracheal intubation are one of the most invasive stimuli in anaesthesia [1]. The tremendous stress response due to these processes results in increased level of catecholamines leading to tachycardia and hypertension. Evidence from laboratory data demonstrates that epipharyngeal and laryngopharyngeal stimulation augments cervical sympathetic activity in the heart. This explains the increase in plasma levels of norepinephrine and to lesser extent epinephrine which occurring during airway instrumentation $[2,3]$.

This stress response is usually well tolerated by normotensive patients, but even short lasting stimulation in patient with recent myocardial infarction, hypertension, pre-eclampsia, thyrotoxicosis and cerebrovascular pathology has been associated with increased morbidity and mortality [4].

As the control of blood pressure and heart rate is of utmost importance to prevent the detrimental effects, there is a need of safe and effective drug to attenuate the cardiovascular response to laryngoscopy and intubation. No pharmaceutical agent to date has been absolutely free of complications in part due to the unique chemical characteristics of each drug and their interaction with the individual biological system of each patient.

$\beta$-blockers like esmolol have shown to be effective in maintenance of hemodynamic stability following endotracheal intubation and laryngoscopy with adequate safety and effectiveness. It has also shown to have an excellent opiate-sparing effect for management of post-operative pain. It has been found to control the blood pressure by optimizing the heart rate, in a dose-dependent manner $[5,6]$.

The suppression of neuro-haemodynamic response to laryngoscopy and intubation has been tried out using other drugs also, such as gabapentin and $\alpha$-agonists (clonidine and dexmedetomidine). Gabapentin, an anticonvulsant has also shown to attenuate pressor response to direct laryngoscopy and tracheal intubation similar to clonidine $[7,8]$.

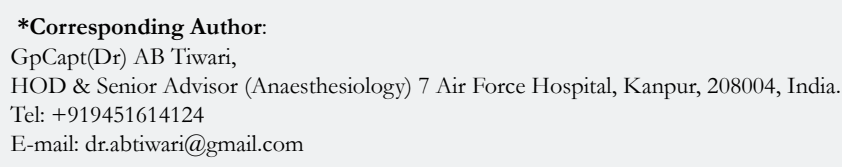

Citation: AB Tiwari, Bhardwaj G, Mestha N. Comparative Study of the Effects of Gabapentin and Esmolol on Hemodynamic Response to Laryngoscopy and Intubation. Int J Anesth Res. 2018;6(8):545-549. doi: http://dx.doi.org/10.19070/2332-2780-18000110

Copyright: AB Tiwari ${ }^{\circ}$ 2018. This is an open-access article distributed under the terms of the Creative Commons Attribution License, which permits unrestricted use, distribution and reproduction in any medium, provided the original author and source are credited. 
Given these variable characteristics of two drugs, the present study has been formulated to provide an insight through a prospective randomized double blind trial. The aim was to evaluate and compare the efficacy of gabapentin and esmolol for attenuation of laryngoscopy/endotracheal intubation induced pressor response. This aim was fulfilled with the help of measuring the change in blood pressure (SBP, DBP, MAP) and heart rate following laryngoscopy/endotracheal intubation among patients receiving gabapentin and esmolol as premedication. Further the incidence of side effects such as headache, nausea, vomiting were also recorded.

\section{Material \& Method}

After permission from Hospital Ethics Committee and written informed consent, patients undergoing laryngoscopy or endotracheal intubation under general anaesthesia for diagnostic/therapeutic purposes in ASA Grade I/II, aged 18 to 60 years were enrolled in study. The sample size calculated [9].

$\mathrm{N}=(r+1)\left(\mathrm{Z}_{\alpha / 2}+\mathrm{Z}_{1-\beta}\right)^{2} \sigma^{2} / r d^{2}$

Where $Z_{\alpha}$ is the normal deviate at a level of significance $\left(Z_{\alpha}\right.$ is 1.96 for $5 \%$ level of significance and 2.58 for $1 \%$ level of significance) and $Z_{1-\beta}$ is the normal deviate at $1-\beta \%$ power with $\beta \%$ of type II error $(0.84$ at $80 \%$ power and 1.28 at $90 \%$ statistical power). $\mathrm{r}=\mathrm{n} 1 / \mathrm{n} 2$ is the ratio of sample size required for 2 groups, generally it is one for keeping equal sample size for 2 groups If $\mathrm{r}$ $=0.5$ gives the sample size distribution as $1: 2$ for 2 groups. $\sigma$ and $\mathrm{d}$ are the pooled standard deviation and difference of means of 2 groups respectively. Where $\mathrm{d}=6.5 \mathrm{mmHg}$ (post-intubation MAP difference), $\sigma=15.5 \mathrm{~mm} \mathrm{Hg}$ (pooled standard deviation), $\mathrm{Z}_{\alpha / 2}=$ 1.96 at $95 \%$ confidence, $Z_{\beta}=0.84$ at $80 \%$ power $=46.324 \sim 46$. The sample size was estimated and to obviate observational bias was kept 60 for each group.

A prospective, randomized, double blind, comparative study carried out where the patients were randomly divided into two equal groups. The Group I patients were given $600 \mathrm{mg}$ gabapentin oral and $10 \mathrm{ml}$ of normal saline as placebo before laryngoscopy/intubation and Group II were given $600 \mathrm{mg}$ placebo oral and Esmolol $1.5 \mathrm{mg} / \mathrm{kg}$ diluted up to $10 \mathrm{ml}$ before laryngoscopy/intubation. Patients were fasted for six hours before study. All patients were premedicated with Midazolam $0.05 \mathrm{mg} / \mathrm{kg}$, Glycopyrrolate 0.004 $\mathrm{mg} / \mathrm{kg}$ and Fentanyl $1 \mathrm{mcg} / \mathrm{kg}$ intravenous. After preoxygenation with 100\% oxygen anaesthesia was induced with Propofol $2 \mathrm{mg} /$ $\mathrm{kg}$, and intubated and maintained with Vecuronium $0.1 \mathrm{mg} / \mathrm{kg}$ intravenous. Minimal monitoring was adhered, basal haemodynamic parameters (pulse rate, SBP, DBP and MAP) were recorded preoperatively and at $1,3,5$ and 10 min post intubation.

The statistical analysis was done using SPSS (Statistical Package for Social Sciences) Version 15.0 statistical Analysis Software. The values were represented in Number, (\%) and Mean \pm SD. The Statistical methods used were Chi square test, Student ' $t$ ' test, paired 't' test, Mann-Whitney U test and Wilcoxon Signed Rank Statistic $\mathrm{W}+$.

\section{Result}

A total of 120 patients of ASA Grade I and II were included in the study, divided in two equal groups. The demographic distribution of patients for age, height, weight, BMI and gender was statistically analyzed and found non-significant $(\mathrm{p}>0.05)$ (Table 1). The baseline recording of hemodynamic variables i.e. heart rate, systolic blood pressure, diastolic blood pressure and mean arterial pressure of Group I and Group II was statistically not significant $(\mathrm{p}>0.05)$ (Table 2).

The heart rate of Group I was higher and statistically significant at 0 -min post-intubation $(\mathrm{p}<0.001)$ while at $1,3,5$ and $10 \mathrm{~min}$ post-intubation periods heart rate of Group II was found to be higher than that of Group I, but this difference was statistically not significant. The SBP, DBP and MAP measured at induction, $0 \mathrm{~min}$ and at $1 \mathrm{~min}$ post-intubation was found to be generally higher in Group I patients and this difference was found to be statistically significant. However the difference in SBP, DBP and MAP measured at $3 \mathrm{~min}, 5 \mathrm{~min}$ and $10 \mathrm{~min}$ post-intubation was statistically not significant.

The statistical analysis of intragroup haemodynamic recorded at specific time intervals revealed that there was significant rise in all parameters since induction till recoding at $0 \mathrm{~min}, 1 \mathrm{~min}, 3 \mathrm{~min}$ and 5 min post-intubation intervals. However there was no significant difference in haemodynamics after post 5 min recordings.

\section{Discussion}

Short-term hemodynamic changes and cardiovascular stress is a characteristic adverse effect of laryngoscopy and tracheal intubation which is attributed to increased catecholamine follow-

Table 1. Demographic Data.

\begin{tabular}{|c|c|c|c|c|c|c|c|c|}
\hline \multirow{2}{*}{ Sr. No. } & \multirow{2}{*}{\multicolumn{2}{|c|}{$\begin{array}{c}\text { Demographic Characteris- } \\
\text { tics (Variables) }(\mathrm{N}=120)\end{array}$}} & \multicolumn{2}{|c|}{ Group I $(n=60)$} & \multicolumn{2}{|c|}{ Group II $(n=60)$} & \multicolumn{2}{|c|}{ Statistical significance } \\
\hline & & & Mean & SD & Mean & SD & 'p' value & 't' value \\
\hline 1 & \multicolumn{2}{|c|}{ Age (year) } & 35.65 & 11.13 & 37.45 & 10.90 & $p=0.467$ & $\mathrm{t}=0.731$ \\
\hline 2 & \multicolumn{2}{|c|}{ Height (m) } & 1.59 & 0.08 & 1.60 & 0.06 & $p=0.796$ & $\mathrm{t}=0.260$ \\
\hline 3 & \multicolumn{2}{|c|}{ Weight $(\mathrm{kg})$} & 64.15 & 5.95 & 64.63 & 5.72 & $\mathrm{p}=0.717$ & $t=0.364$ \\
\hline 4 & \multicolumn{2}{|c|}{ BMI $\left(\mathrm{kg} / \mathrm{m}^{2}\right)$} & 25.24 & 3.48 & 25.13 & 1.72 & $\mathrm{p}=0.856$ & $\mathrm{t}=0.182$ \\
\hline \multirow{2}{*}{5} & \multirow{2}{*}{ Sex } & Male & 31 & $77.5 \%$ & 28 & $70.0 \%$ & \multirow{2}{*}{$\mathrm{p}=0.306$} & \multirow{2}{*}{--} \\
\hline & & Female & 9 & $22.5 \%$ & 12 & $30.0 \%$ & & \\
\hline
\end{tabular}

(P value $<0.05=$ statistically significant, $\mathrm{P}$ value $<0.001=$ statistically highly significant) 
ing sympathoadrenal discharge caused by epipharyngeal and parapharyngeal stimulations that eventually results in increase in heart rate, blood pressure, myocardial oxygen demand, and dysrhythmias $[2,3]$. The change in cardiovascular parameters is most prominent following laryngoscopy and intubation with an average increase in blood pressure by $40-50 \%$ and an average increase of $20 \%$ in heart rate $[10]$.

The two groups were matched demographically for age and gender and baseline hemodynamics, thus showing no confounding effect of these variables. Although some studies report bradycardia as a side effect associated with gabapentin, however, in present study between baseline and induction interval gabapentin showed a comparable effect on heart rate. An increase in heart rate between baseline and induction intervals might be attributed to operative room anxiety. Shrestha et al., observed only a nominal increase in heart rate between baseline and induction intervals $(3.0 \%)$ in gabapentin group, however, in esmolol group they found $6.39 \%$ decline in heart rate during the same period [11]. However Reddy et al., and Srivastava et al., in their studies found a nominal increase in heart rate between baseline and induction intervals $[12,13]$.

However, following intubation, the attenuation effect of gabapentin on heart rate was minimal compared to esmolol group, similar to observation by Shrestha et al; showed a mean increase nearly $25 \%$ in gabapentin group whereas in esmolol group they showed a mean decline of $2.8 \%$. However, from 1 min post-intubation onward both the groups showed a tendency to diminish the gap from baseline values and by $10 \mathrm{~min}$, both the groups achieved mean heart rate comparable to corresponding baseline values. With respect to comparison between two groups, the difference between two groups was significant statistically only at immediate post-intubation interval. Thus showing that either the pressor response in terms of heart rate was too transient or the attenuating effect of two drugs acted differently at different post-intubation intervals.

In another study, it was found gabapentin to be quite effective in controlling post-intubation heart rate, however in their study, the dosage of gabapentin used was more than twice $(1600 \mathrm{mg})$ than that used in present study $(600 \mathrm{mg})$ [8]. Failure of gabapentin $(600$ $\mathrm{mg}$ ) to attenuate heart rate increments following laryngoscopy and endotracheal intubation as observed in present study has also been reported in some other studies too [14]. Using lower dose of gabapentin (400 mg) as compared to that used in present study $(600 \mathrm{mg})$, failed to achieve a blunting effect on heart rate. Similar observations were also reported in other studies [15].

Response to heart rate increases following laryngoscopy and endotracheal intubation has been shown to be promising at higher dosages (800mg and above) of gabapentin [7, 16]. In present study too, though the immediate response of gabapentin was poor yet at subsequent assessments it was as effective as esmolol, similar observation was made by Iftikhar et al., [17]. Nanda et al., too confirmed that Gabapentin does not complete attenuate the heart rate increases following intubation [18].

The findings in present study in light of the findings in literature showed that as far as heart rate is concerned, at the given dose as used in present study, gabapentin has a limited effect on heart rate (Table 4). As such, gabapentin's heart rate attenuating effect is concerned it is extremely dose dependent as could be analyzed in comparative assessment of different studies.

In present study, at baseline both the groups did not have a significant difference in mean systolic, diastolic and mean arterial blood pressure.

One must not forget that despite the fast onset of hypotensive effect of esmolol, which is administered just 2 minutes before induction, the fall in blood pressure is not such rapid so as to make

Table 2. Baseline Hemodynamic Variables.

\begin{tabular}{|c|c|c|c|c|c|c|}
\hline \multirow{2}{*}{ Variables } & \multicolumn{2}{|c|}{$\begin{array}{c}\text { Group I } \\
(\mathbf{n = 6 0})\end{array}$} & \multicolumn{2}{c|}{$\begin{array}{c}\text { Group II } \\
(\mathbf{n = 6 0 )}\end{array}$} & \multicolumn{2}{c|}{$\begin{array}{c}\text { Statistical } \\
\text { significance }\end{array}$} \\
\cline { 2 - 7 } & Mean & SD & Mean & SD & 't' & 'p' \\
\hline Heart rate (per min) & 76.17 & 7.08 & 77.93 & 7.32 & -1.344 & 0.182 \\
\hline Systolic BP (mm Hg) & 127.2 & 8.87 & 127.2 & 11.03 & 0.000 & 1.000 \\
\hline Diastolic BP (mm Hg) & 72.6 & 5.42 & 74.1 & 4.14 & -1.704 & 0.091 \\
\hline Mean arterial pressure $(\mathrm{mm} \mathrm{Hg})$ & 90.74 & 6.2 & 91.81 & 5.13 & -1.03 & 0.305 \\
\hline
\end{tabular}

Table 3. Inter Group Variation In Haemodynamics.

\begin{tabular}{|c|c|c|c|c|}
\hline \multirow{2}{*}{ Time intervals } & \multicolumn{4}{|c|}{ 'p' Value } \\
\cline { 2 - 5 } & Heart Rate & SBP & DBP & MAP \\
\hline Baseline & 0.182 & 1.000 & 0.091 & 0.305 \\
\hline At induction & 0.522 & $<0.001$ & $<0.001$ & $<0.001$ \\
\hline 0 min post-intub & $<0.001$ & $<0.001$ & 0.001 & $<0.001$ \\
\hline 1 min post-intub & 0.116 & $<0.001$ & $<0.001$ & $<0.001$ \\
\hline 3 min post-intub & 0.31 & 0.260 & 0.388 & 0.23 \\
\hline 5 min post-intub & 0.657 & 0.686 & 0.002 & 0.015 \\
\hline 10 min post-intub & 0.053 & 0.001 & 0.01 & $<0.001$ \\
\hline
\end{tabular}


Table 4. Intragroup Variation in Haemodynamics.

\begin{tabular}{|c|c|c|c|c|c|c|c|c|}
\hline \multirow{2}{*}{ Recording Intervals } & \multicolumn{4}{|c|}{ Group I } & \multicolumn{4}{c|}{ Group II } \\
\cline { 2 - 9 } & Heart rate & SBP & DBP & MAP & Heart rate & SBP & DBP & MAP \\
\hline At induction & $<0.001$ & $<0.001$ & $<0.001$ & $<0.001$ & $<0.001$ & 0.008 & 0.276 & 0.056 \\
\hline 0 min post intub & $<0.001$ & $<0.001$ & $<0.001$ & $<0.001$ & $<0.001$ & $<0.001$ & $<0.001$ & $<0.001$ \\
\hline 1 min post intub & $<0.001$ & $<0.001$ & $<0.001$ & $<0.001$ & $<0.001$ & $<0.001$ & $<0.001$ & $<0.001$ \\
\hline 3 min post intub & $<0.001$ & $<0.001$ & $<0.001$ & $<0.001$ & $<0.001$ & $<0.001$ & $<0.001$ & $<0.001$ \\
\hline 5 min post intub & $<0.001$ & 0.008 & 0.285 & 0.095 & $<0.001$ & $<0.001$ & $<0.001$ & $<0.001$ \\
\hline 10 min post intub & 0.697 & 0.021 & $<0.001$ & $<0.001$ & 0.810 & $<0.001$ & 0.122 & 0.002 \\
\hline
\end{tabular}

some noticeable change.

However, despite this preemptive arrangement, following intubation, mean blood pressure values (SBP, DBP and MAP) were either significantly higher in gabapentin group as compared to esmolol group or did not show a significant difference between two groups.

Considering the pressor response changes for blood pressure to be nearly $40-50 \%$ of baseline values, although both the groups showed a significant attenuation of response, yet the response was significantly higher in esmolol as compared to gabapentin group.

Esmolol is a short acting rapid onset drug, It has a half-life of only $9 \frac{1}{2}$ minutes and hence it provides a better immediate attenuating action as compared to Gabapentin which has an onset duration of 2-3 hours but it has long-acting effect with plasma half-life 5-7 h. Gabapentin is unable to provide immediate attenuating effect whereas Esmolol in a short time gap between induction and intubation achieves the peak value and thus in turn is able to blunt the pressor response from $40-50 \%$ to only $5-10 \%$. On the contrary, gabapentin acts on the preemptive reduction in blood pressure values which are less elastic to respond during a short course. At high dosages, it has shown to display protective effect, however, at lower dosages it does not provide protection. However, owing to its prolonged onset duration, at higher dosages, it might induce hypotension and might in turn have deleterious rather than protective prior to and after the pressor responses following intubation.

However, even at larger dosages, its attenuating response is partial. In a study gabapentin $(800 \mathrm{mg}$ ) was shown to have failed in providing elimination of tachycardia response [19]. Comparatively, esmolol has been found to provide a better pressor response as compared to other drugs and hence a better option as compared to gabapentin [20].

In one such comparative study between esmolol and gabapentin, where a much higher dosages of gabapentin $(1200 \mathrm{mg})$ was used as compared to that in present study $(600 \mathrm{mg})$ and showed gabapentin to have an edge. However, given the safety concerns related with high dosages of gabapentin, these high dosages are subject to scrutiny. Moreover, the cited study had groups comprising of 18 patients each which is too fewer to have enough effect size to be replicable [11].

In present study, in a relatively larger study with lower dosages of gabapentin we found it to have a poorer performance in comparison to Esmolol while evaluating its attenuating effect on pressor response following laryngoscopy and intubation. This being probably the second study in literature to compare the two drugs and in view of the contradictory yet rational (owing to difference in dosages) results, this issue warrants further evaluation. There is need to settle an optimum dose of gabapentin which may provide sufficient attenuating effect without any safety risk. Hence, we recommend further studies on same dosages as well as variables dosages of two drugs to build empirical evidence in either direction. No post-operative side effects or complications had been reported by any of the patients included in the study.

\section{Conclusion}

On the basis of above observations, it can be concluded that Mean blood pressure (SBP, DBP, and MAP) and heart rate following laryngoscopy and endotracheal intubation was better controlled in Esmolol group as compared to gabapentin. Though none of the groups showed any side effect or complication, yet risk of hypotension and bradycardia was more common in gabapentin group owing to great decline in blood pressure and heart rate between baseline and induction intervals. In our study esmolol outscored gabapentin in controlling the pressor responses of laryngoscopy and endotracheal intubation. Further studies on variable dose profiles for both the drugs are recommended.

\section{References}

[1]. Randell T. Haemodynamic responses to intubation: what more do we have to know?. Acta Anaesthesiol Scand. 2004 Apr;48(4):393-5. PubMed PMID: 15025596.

[2]. Kovac AL. Controlling the hemodynamic response to laryngoscopy and endotracheal intubation. J Clin Anesth. 1996 Feb;8(1):63-79. PubMed PMID: 8695083.

[3]. Kayhan Z, Aldemir D, Mutlu H, Ögüş E. Which is responsible for the haemodynamic response due to laryngoscopy and endotracheal intubation? Catecholamines, vasopressin or angiotensin?. Eur J Anaesthesiol. 2005 Oct;22(10):780-5. PubMed PMID: 16211744.

[4]. Morin AM, Geldner G, Schwarz U, Kahl M, Adams HA, Wulf H, et al. Factors influencing preoperative stress response in coronary artery bypass graft patients. BMC Anesthesiol. 2004 Sep 23;4(1):7. PubMed PMID: 15387891.

[5]. Miller DR, Martineau RJ, Wynands JE, Hill J. Bolus administration of esmolol for controlling the haemodynamic response to tracheal intubation: the Canadian Multicentre Trial. Can J Anaesth. 1991 Oct;38(7):849-58. PubMed PMID: 1683818

[6]. Collard V, Mistraletti G, Taqi A, Asenjo JF, Feldman LS, Fried GM, et al. Intraoperative esmolol infusion in the absence of opioids spares postoperative fentanyl in patients undergoing ambulatory laparoscopic cholecystectomy. Anesth Analg. 2007 Nov;105(5):1255-62. PubMed PMID: 17959952.

[7]. Montazeri K, Kashefi P, Honarmand A, Safavi M, Hirmanpour A. Attenuation of the pressor response to direct laryngoscopy and tracheal Intuba- 
tion: oral clonidine vs. oral gabapentin premedication. J Res Med Sci. 2011 Mar;16 Suppl 1:S377-86. PubMed PMID: 22247722.

[8]. Fassoulaki A, Melemeni A, Paraskeva A, Petropoulos G. Gabapentin attenuates the pressor response to direct laryngoscopy and tracheal intubation. $\mathrm{Br} \mathrm{J}$ Anaesth. 2006 Jun;96(6):769-73. PubMed PMID: 16595614.

[9]. Suresh KP, Chandrashekara S. Sample size estimation and power analysis for clinical research studies. J Hum Reprod Sci. 2012 Jan;5(1):7-13. doi: 10.4103/0974-1208.97779. PubMed PMID: 22870008.

[10]. Bruder N, Ortega D, Granthil C. Consequences and prevention methods of hemodynamic changes during laryngoscopy and intratracheal intubation. Ann Fr Anesth Reanim. 1992;11(1):57-71. PubMed PMID: 1359816.

[11]. Shrestha GS, Marhatta MN, Amatya R. Use of Gaba-pentin, Esmolol, or Their Combination to Attenuate Haemodynamic Response to Laryngoscopy and Intu-bation. Kathmandu Univ Med J. 2011;36(4):238-43. PubMed: 22710530.

[12]. Reddy SV, Balaji D, Ahmed SN. Dexmedetomidine versus esmolol to attenuate the hemodynamic response to laryngoscopy and tracheal intubation: A randomized double-blind clinical study. Int J Appl Basic Med Res. 2014 Jul;4(2):95-100. doi: 10.4103/2229-516X.136788. PubMed PMID: 25143884

[13]. Srivastava VK, Agrawal S, Gautam SK, Ahmed M, Sharma S, Kumar R. Comparative evaluation of esmolol and dexmedetomidine for attenuation of sympathomimetic response to laryngoscopy and intubation in neurosurgical patients. J Anaesthesiol Clin Pharmacol. 2015 Apr-Jun;31(2):186-90. doi: 10.4103/0970-9185.155146. PubMed PMID: 25948898.
[14]. Bafna U, Goyal VK, Garg A. A comparison of different doses of gabapentin to attenuate the haemodynamic response to laryngoscopy and tracheal intubation in normotensive patients. J Anaesthesiol Clin Pharmacol. 2011 Jan;27(1):43-6. PubMed PMID: 21804705.

[15]. Memiş D, Turan A, Karamanlığlu B, Şeker Ş, Türe M. Gabapentin reduces cardiovascular responses to laryngoscopy and tracheal intubation. Eur J Anaesthesiol. 2006 Aug;23(8):686-90. PubMed PMID: 16805934.

[16]. Ayatollahi V, Mirshamsi P, Behdad S, Amirdosara M, Vaziribozorg S. Effect of oral gabapentin on haemodynamic variables during microlaryngoscopic surgery. Anaesthesiol Intensive Ther. 2014 Jan-Mar;46(1):17-22. doi: 10.5603/AIT.2014.0004. PubMed PMID: 24643922.

[17]. Iftikhar T, Taqi A, Sibtain A, Anjum S, Awan I. Oral gabapentin reduces hemodynamic response to direct laryngoscopy and tracheal intubation. Anesth Pain Intensive Care. 2011 Jun 1;15:17-21.

[18]. Nanda A, Krishnamurthy D, Madhusudhana R, Potli S. Comparative study of clonidine and gabapentin for attenuating hemodynamic responses to laryngoscopy and tracheal intubation. IOSR J Dent Med Sci. 2015 Apr;14:110-7.

[19]. Kiran S, Verma D. Evaluation of gabapentin in attenuating pressor response to direct laryngoscopy and tracheal intubation. SAJAA. $2008 \mathrm{Nov}$ $1 ; 14(6): 43-6$.

[20]. Singh H, Vichitvejpaisal P, Gaines GY, White PF. Comparative effects of lidocaine, esmolol, and nitroglycerin in modifying the hemodynamic response to laryngoscopy and intubation. J Clin Anesth. 1995 Feb;7(1):5-8. PubMed PMID: 7772359 . 